\title{
Lower lip reconstruction using a skin-mucosa Abbe-Estlander flap after squamous cell carcinoma excision*
}

Husein Husein-ElAhmed ${ }^{1}$

\author{
Rafael Armijo-Lozano ${ }^{2}$
}

DOI: http:/ / dx.doi.org/10.1590/abd1806-4841.20175269

\begin{abstract}
Lips are structures that play an essential role in aesthetics and in different functions such as nutrition and speech. The complex anatomy of the lips - with three different layers composed of skin, mucosa, and muscles - makes surgical management of this area a therapeutic challenge. The use of flaps for the reconstruction of large defects with low risk of necrosis is possible given the abundant blood supply of the lips. We report a case of surgical reconstruction of the lower lip after the excision of a severe squamous cell carcinoma using a skin-mucosa Abbe-Estlander flap with a satisfactory final outcome.
\end{abstract}

Keywords: Carcinoma, squamous cell; Free tissue flaps; Surgical flaps

\section{INTRODUCTION}

Lips are structures that play an essential role in aesthetics and in different functions such as nutrition and speech. Certain conditions such as cancer, trauma, and congenital deformities are the major causes of lip dysmorphism that require reconstruction. This type of surgery can be challenging due to the complex anatomy of the lips composed of three different layers (skin, mucosa, and muscles). The use of flaps for the reconstruction of large defects with low risk of necrosis is possible given the abundant blood supply of the lips. The Abbe-Estlander flap is a full-thickness lip-switch flap in which a portion of the uninvolved lip (upper or lower) is rotated across the mouth and into the defect of the involved lip. In 1872 Estlander emphasized the importance of the flap. Abbe, in 1898 , was the first to switch a lower lip flap into the upper lip for a cleft deformity. ${ }^{1}$ Although this technique was described more than a century ago, it is currently used in many cases due to its efficiency, safety, good hemostasis, functionality, and positive cosmetic results. Recent reports show that many surgeons still use it in combination with other flaps. ${ }^{2}$ The aim of this work is to report a case of surgical reconstruction of the lower lip using an Abbe-Estlander flap composed of skin and mucosa.

\section{CASE REPORT}

We report a 68-year-old man presenting with a 6-year history of progressive overgrowth of a bullous lesion of the lower lip with loss of its normal contour. The lesion was asymptomatic and occasional itchy. His past medical history revealed hypertension and type II diabetes, for which he was prescribed enalapril $10 \mathrm{mg}$ and metformin $850 \mathrm{mg} /$ daily. He was a former moderate smoker (15 cigarettes/day) and had worked as a farmer. The patient reported no other medical problem or family history of melanoma or

\section{Received on 21.10.2015}

Approved by the Advisory Board and accepted for publication on 19.01.2016

* Work performed at the Hospital San Cecilio - Granada, Spain.

Financial support: none.

Conflict of interest: none.

Department of Dermatology, Hospital de Baza - Granada, Spain.

Department of Dermatology, San Cecilio University Hospital - Granada. Spain. non-melanoma skin cancer. No alcohol consumption was reported.

Physical examination revealed a hyperkeratotic exophytic bullous mass involving more than two-thirds of the lower lip with obliteration of its normal contour (Figure 1). No locoregional lymph nodes were observed.

Based on these features, we made an initial diagnosis of squamous cell carcinoma.

We discussed different surgical options. After considering the size of the lesion and the risks and benefits of the different surgical techniques, we opted for lesion excision followed by reconstruction with an Abbe-Estlander flap.

The procedure was performed under general anesthesia. We used a scalpel with a \#15 blade to remove the lesion with a $5 \mathrm{~mm}$ margin. The flap was designed with parallel planes of skin and


Figure 1: A. Squamous cell carcinoma involving more than twothirds of the lower lip. B. Detailed view of the lesion

C2017 by Anais Brasileiros de Dermatologia 

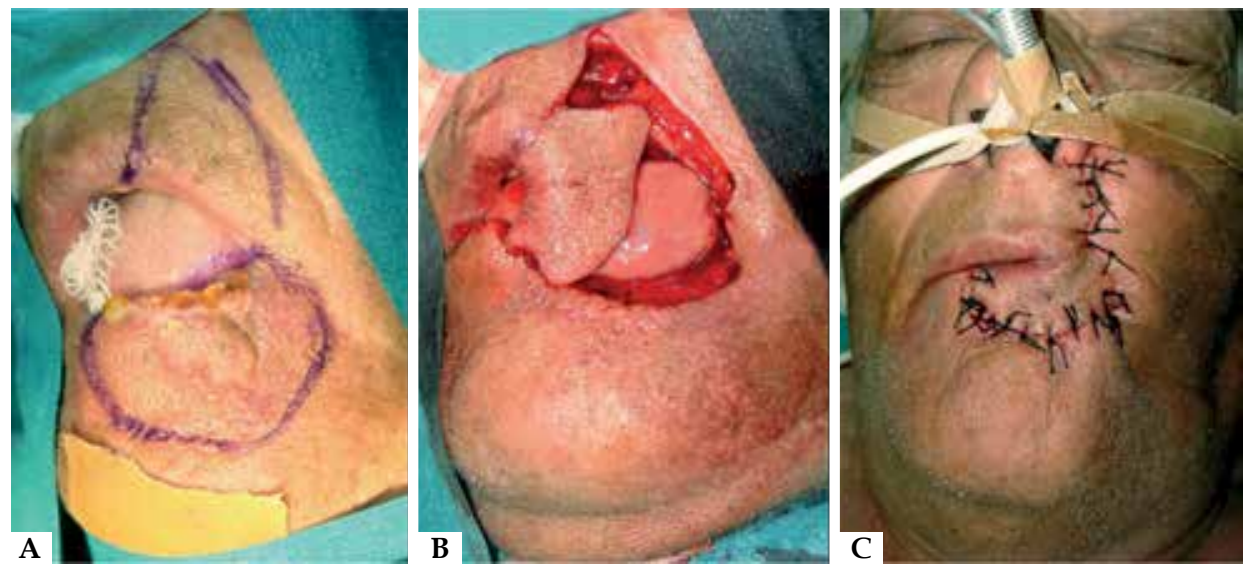

Figure 2: A. Design of the surgical removal and of the skin-mucosa flap. B. The upper flap is swung into position to fill the defect on the lower lip. A new oral commissure is created. C. Immediate postoperative result

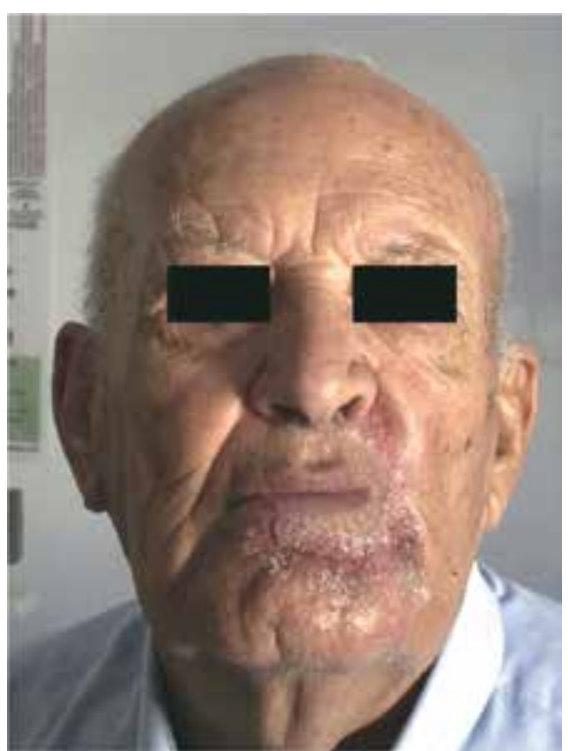

FIGURE 3: Postoperative result after four weeks showing good symmetry of the oral commissures

mucosa in a portion of the upper lip (Figures 2A and 2B). The flap was then advanced and twisted following the wedge resection of the tumor to create a new oral commissure (Figure 2C). A pressure dressing was applied to the entire lower lip for five days. Postoperative period was satisfactory and the patient was followed up closely for dressing changes. The wound healed well two weeks after the intervention. At a one-month follow-up visit, a scar was barely present, with no local complications such as venous return disturbance. The oral commissure was restored with good symmetry (Figure 3). Return of sensation occurred after three months. The overall final outcome was good and the surgery was functionally successful.

\section{DISCUSSION}

Lower lip reconstruction after a squamous cell carcinoma excision can be challenging, particularly when repairing large surgical defects involving the oral commissures. Functional goals of lip reconstruction include maintenance of oral competence, sufficient oral access, and preservation of lip sensation. Besides, good cosmetic outcomes should be reached. Although various methods to reconstruct $1 / 3^{\text {rd }}$ to $2 / 3^{\text {rd }}$ width lower lip defects have been reported, none is considered as "gold standard". In our case, we opted for reconstruction using the Abbe-Estlander flap technique in which a portion of the uninvolved lip is incised and extended to create a new opposite lip vermillion., Although this technique was described more than 150 years ago, it still holds a reliable position as a lip reconstruction method. In a recent review of a series of 10 cases of lip reconstruction by Abbe-Estlander flap, authors observed that nine out of 10 patients (90\%) showed permanent aesthetic oral commissures and $100 \%$ of cases showed good blood supply. ${ }^{5}$

One of the remaining problems of this flap technique is the displacement of the oral commissure, which would lead to asymmetry of the face. In our case, we observed a slight asymmetry, but we think the final outcome was positive considering that the lesion involved more than two-thirds of the lower lip.

In general, the highest degree of aesthetic camouflage in the Abbe-Estlander technique is one of its main advantages. In addition, the return to normal activity is rapid and the complication rate is low. In our patient, wound healing was achieved two weeks after intervention, and the scar was barely noticeable after one month. Other techniques for lip reconstruction such as secondary healing and skin grafts show a tendency for contraction and significant risk of distortion. Besides, these techniques offer worse color matches. ${ }^{6,7}$ Skin grafts are only used in high-risk lesions or in situations when flap reconstruction is not readily available. ${ }^{6,7}$

Clinicians should make every attempt to preserve function and cosmetic appearance of a patient when choosing a reconstructive approach to address a lower lip defect. Abbe-Estlander flap is one of the mainstays of lip reconstruction since it shows good results with minimum morbidity if performed by experienced hands.

The Abbe-Estlander method is useful for the reconstruction of defects affecting $1 / 3^{\text {rd }}$ to $2 / 3^{\text {rd }}$ of the lip, including the oral commissure. This technique is cosmetically and functionally successful resulting in good symmetry of the oral commissure. $\square$ 


\section{REFERENCES}

1. Franc C, Braye F, Breton P, Freidel M. The Abbe-Estlander flap: anatomic basis, surgical technic and indications for lip repair. Rev Stomatol Chir Maxillofac. 1996;97:92-102.

2. Yamauchi M, Yotsuyanagi T, Ezoe K, Saito T, Yokoi K, Urushidate S. Estlander flap combined with an extended upper lip flap technique for large defects of lower lip with oral commissure. J Plast Reconstr Aesthet Surg. 2009;62:997-1003.

3. Roldán JC, Teschke M, Fritzer E, Dunsche A, Härle F, Wiltfang J, et al. Reconstruction of the lower lip: rationale to preserve the aesthetic units of the face. Plast Reconstr Surg. 2007;120:1231-9.

4. Maillard GF. Surgical treatment of lip precanceroses and neoplasms. Schweiz Med Wochenschr. 1978;108:920-2.

5. Kumar A, Shetty PM, Bhambar RS, Gattumeedhi SR, Kumar RM, Kumar H. Versatility of abbe-estlander flap in lip reconstruction - a prospective clinical study. J Clin Diagn Res. 2014;8:NC18-21.

6. Cupp CL, Larrabee WF. Reconstruction of the lips. Oper Tech Otolaryngol Head Neck Surg. 1993:4:46-53.

7. Dzubow, LM. Rotation flaps. In: Dzubow LM, editor. Facial flaps, biomechanics and regional application. Norwalk, CT: Appleton and Lange; 1990. p.31-41
MAILING ADDRESS:

Husein Husein-ElAhmed

Avda Madrid, s/n

18012 Madrid - Spain

E-mail: huseinelahmed@hotmail.com

How to cite this article: Husein-ElAhmed H, Armijo-Lozano R. Lower lip reconstruction using a skin-mucosa Abbe-Estlander flap after squamous cell carcinoma excision. An Bras Dermatol. 2017;92(2):260-2. 